\title{
Effects of Video Lecture Design and Production Quality on Student Outcomes: A Quasi-Experiment Exploiting Change in Online Course Development Principles
}

\author{
Marketa Rickley ${ }^{1}$ and Pavlina Kemp ${ }^{2}$ \\ ${ }^{1}$ University of North Carolina at Greensboro, NC, USA \\ ${ }^{2}$ University of lowa Hospitals and Clinics, Iowa City, IA, USA \\ m rickle@uncg.edu \\ pavlina-kemp@uiowa.edu
}

\begin{abstract}
In seeking competitive advantage, many online graduate programs have turned to improving the quality of video lectures by investing in instructional designers and in-studio production. However, it is unclear how much video lecture design and production quality improve student outcomes. We used a regression discontinuity to evaluate how video lecture design and production practices that adhere to principles of multimedia learning affect perceived learning and student satisfaction. The study involved 300 students taking an online graduate course at a large, public research university, where 194 students were exposed to video lectures designed and produced by the instructor and 106 students were exposed to video lectures designed in collaboration between the instructor and instructional designers and produced in studio. Our findings indicate that designing and producing video lectures in accordance with principles of multimedia learning has a meaningful causal effect on students' perceived learning and a marginal effect on student satisfaction. We discuss the theoretical and practical implications of our findings for video lecture development and design in the context of online business education and the COVID-19 pandemic.
\end{abstract}

Keywords: Video lectures; Online learning; Cognitive Theory of Multimedia Learning; Instructional design; MBA program

\section{Introduction}

As of 2019, 46 percent of faculty members in the United States reported having taught an online course for credit (Jaschik and Lederman, 2019). In 2020, the experience became nearly universal when educational institutions transitioned to remote teaching. Yet there is a substantial disparity in how faculty members develop and design online course content (Fiorella, et al., 2017). Inside Higher Ed's 2019 Survey of Faculty Attitudes on Technology indicates that 62 percent of faculty members developed and designed online courses on their own, while 17 percent of faculty members created all or most of their courses in collaboration with instructional designers (Jaschik and Lederman, 2019). Quality Matters' 2019 survey of Chief Online Officers at U.S. higher education institutions concluded that use of instructional design support remains low due to two factors: "Cost is an ongoing constraint, and entrenched faculty ... resistant to surrendering any of their autonomy in the online or on-ground classroom persist in many institutions." (Garrett, Legon and Fredericksen, 2019, p.24)

The apparent disconnect between theory and practice of online course development, design, and production is puzzling given the substantial advances in online learning research. Unlike two decades ago when educational theory for online learning was in its infancy, today there is increasing convergence in scientific thought on best practices in online learning (e.g., Clark and Mayer (2011); Mayer (2009); Mayer (2005); Jenlink (2019), among others).

We examine how much adopting best practices matters for student outcomes in the context of designing and producing online video lectures. Video lectures are a central element in online learning. They are instructors' primary means of presenting information (de Koning, Hoogerheide and Boucheix, 2018) and students rank them as the most valuable class activity for learning and success (Magda and Aslanian, 2018). Importantly, video lectures increase instructors' teaching and social presence in the virtual classroom (Draus, Curran and Trempus, 2014; Ke, 2010). Teaching and social presence are in turn linked to key outcomes such as student participation, engagement, and satisfaction (Garrison and Arbaugh, 2007).

Best practices in video lecture design and production are informed by principles of multimedia learning (Mayer, 2014a), which were developed for the purpose of optimizing learning from visual and verbal content using theories of learning and cognition (Baddeley, 1986; Paivio, 1990; Sweller, 1988, 1994). We define professionallyproduced video lectures as those created in collaboration between instructors as the subject matter experts and 
instructional designers whose primary role is to advise on pedagogical principles (Kenny, et al., 2005). They are recorded in studio by digital media production professionals. Yet instructors face few barriers to producing video lectures on their own (Kizilcec, Bailenson and Gomez, 2015; de Koning, Hoogerheide and Boucheix, 2018). Using commonly available technology, such as computers, smartphones, video or web cameras, video recording software, video-editing applications, and a high-speed internet connection, instructors can create and disseminate video lectures quite easily and cost efficiently.

Indeed, the seemingly low barriers to producing online learning content have enabled institutions of higher education to respond to the COVID-19 pandemic by asking instructors to transform courses previously taught face-to-face into an online format, virtually overnight. But, just as conducting education at a distance is not the same as delivering a quality education online, exposing students to instructors' best efforts to design and produce video lectures is not the same as exposing them to video lectures designed and produced in accordance with principles of multimedia learning. Moreover, institutions vary greatly in how they prepare and support instructors who are teaching online and instructors themselves vary in their abilities to create engaging and effective video lectures. Consequently, "the quality of faculty-created videos varies from magical to marginal." (Mosley, 2017, p.92) Given these realities, the purpose of our study is to measure the difference in student outcomes among students exposed to video lectures that are designed and produced in adherence with basic principles of multimedia learning compared to video lectures that are developed by the instructor.

This study identifies the causal effect of video lecture design and production on perceived learning and student satisfaction using a discontinuity in online course development standards at a large, public research university. A 2017 decision put into effect a requirement that all online courses in the Master of Business Administration (MBA) program be designed and developed in collaboration between instructors, instructional designers, and digital media professionals. Importantly, the requirement applied not only to new courses yet to be developed, but also to existing courses previously developed by instructors. Our research design takes advantage of this discontinuous change in development standards to assess the effect of a change in video lecture design and production quality in the context of a single online course that was taught nine times between the years 2016 and 2019. In this core MBA course, all course components remained the same over this four-year period, apart from the video lectures. This feature allows us to employ a regression discontinuity design to measure and compare student satisfaction and perceived learning pre- and post-intervention in video lecture design and production.

We make several contributions to multimedia and online learning literature. First, our research informs the current scholarly debate on video lecture efficacy by examining the combined effect of instructional design and professional production of video lectures on student outcomes. As such, it answers a call in the literature for examining how video lecture design features relate to learning outcomes (Crook and Shofield, 2017). Second, our study provides much needed empirical evidence from graduate students taking full-semester online courses. There is currently a dearth of research on the impact of video lectures in graduate education. Our understanding of how video lectures affect student outcomes rests on findings from laboratory studies of Amazon Mechanical Turk participants (e.g., Wilson, et al. (2018)), undergraduate students (often outside the United States) (e.g., van Wermeskerken, Ravensbergen and van Gog (2018); van Wermeskerken and van Gog (2017); Hong, Pi and Yang (2018); Chen and Wu (2015)), and massive open online courses (MOOCs) (Kizilcec, Bailenson and Gomez, 2015; Bhat, Chinprutthiwong and Perry, 2015). The generalizability of the available research on video lectures to online graduate education is debatable. Our field research, in contrast, is highly relevant for other graduate-level online business programs as it assesses satisfaction and learning outcomes of students taking a core course at an AACSB-accredited and nationally ranked MBA program.

This study also has important practical implications for institutions offering online courses. Given our field setting, our findings can inform future institutional decision making about resource allocation. If our findings indicate that video lecture design and production quality improve student outcomes, then institutions can better justify expenditures into instructional designers, production studios, and related staff - and these costs are far from trivial. Indeed, after accounting for key resources (such as subject matter experts, instructional designers, and technical staff) estimates suggest that designing and developing one hour of online learning content in adherence with online education best practices can range from $\$ 7,800$ up to $\$ 37,400$ (Movchan, et al., 2019). Of this sum, the costliest component is the time and money spent on designing, producing, and editing the video lecture (Movchan, et al., 2019). 
Finally, our findings contribute much needed data and evidence to faculty members and administrators as they manage the new academic landscape created by the COVID-19 pandemic. During the forced emergency transition to online instruction this spring, faculty members self-produced entire online courses at extremely short notice. While the quality of online instruction sufficed for the moment, students' expectations are already rising ahead of the Fall 2020 semester and institutions are under pressure to increase the quality of online instruction during the summer months. This study is timely and relevant to the current global conversation about online learning as it quantifies the effect of instructional design and professional production of online course content on student outcomes.

\section{Theory and Hypothesis Development}

Video lectures are a central component of online education. They are the primary means of delivering instruction in online undergraduate and graduate courses (de Koning, Hoogerheide and Boucheix, 2018). The most common video lecture types can be summarized as follows: slides (slide presentation with voice-over lecture by the instructor); Khan whiteboard (full-screen video of instructor drawing or writing freehand on a digital tablet); classroom (video recording of a classroom lecture); office desk (video recording of instructor's head or torso speaking at an office desk); and studio (instructor is recorded in a studio with no audience) (Crook and Shofield, 2017; Guo, Kim and Rubin, 2014). A video lecture can include multiple styles either in sequence or simultaneously by embedding separate windows with different styles.

An important theoretical perspective that informs research on the effects of design and production in video lectures is the Cognitive Theory of Multimedia Learning (CTML, Mayer (2014a)). CTML is an evidence-based theory that joins the science of learning with the science of instruction. Its theoretical foundations are rooted in learning and cognition science, including working memory (Baddeley, 1986), dual-coding (Paivio, 1990), and cognitive load theory (CLT, Sweller (1988; 2005)).

The premise of CTML is that "people learn more deeply from words and pictures than from words alone" (Mayer, 2014b, p.43). In cognitive theories of learning, learners have limited capacity and information processing ability (Miller, 1956). They are constrained by their cognitive ability to select and organize information and integrate it into long-term memory (Paas and Sweller, 2014; Sweller, 1988). How to optimize the presentation of words and pictures to guide people's learning processes most effectively and efficiently is thus the central question that CTML scholars seek to answer (Mayer, 2014a).

Three assumptions developed in cognitive science underlie CTML. First, the dual channels assumption states that people process visual and auditory information through separate channels (Paivio, 1990; Baddeley, 1992). Multimedia that uses both channels can therefore increase the amount of information a learner's brain can process (Mayer, 2009; Penney, 1989), leading to quicker comprehension and richer mental representations than would be possible through verbal or pictorial presentations alone (Sweller, 2005). Second, the active processing assumption states that active learning is the outcome of selecting, organizing, and integrating information with other knowledge (Wittrock, 1989). In other words, learners do not interpret words, pictures, and auditory information in an independent and mutually exclusive fashion. Instead, learners select, organize, and integrate elements in relation to prior knowledge. Multimedia presentations that organize and introduce new knowledge in ways that build on existing mental schemas and logical constructs are more effective.

Finally, the limited capacity assumption states that people are constrained in the amount of information that visual and auditory channels can each process at once (Baddeley, 1992; Chandler and Sweller, 1991; Miller, 1956). Multimedia thus needs to be designed to not overwhelm either channel. Of course, all instructional material imposes demands on learners' ability to process information. This demand is referred to by cognitive scientists as cognitive load. Cognitive load can be divided into three categories: intrinsic, extraneous, and germane (Sweller, 1994). Intrinsic load represents the natural, unalterable difficulty of the material to be learned and it is independent of instructional design efforts (Sweller, 1994). Extraneous load is the processing strain on the learner created by sub-optimal instructional design choices, and it represents the type of load that CLT and CTML researchers strive to minimize. The third category, germane load, represents the cognitive effort required to organize and integrate information into long-term memory (Sweller, 2010). While both intrinsic and extraneous load are determined entirely or in part by the characteristics of the instructional material, germane load depends on the characteristics of the learner and on instructional design choices that enhance the learner's 
ability structure and encode knowledge into memory. Instructional design of multimedia therefore aims to reduce extraneous cognitive processing and free capacity for knowledge integration.

Given CTML's emphasis on optimizing the presentation of words and pictures for learning, its principles are highly salient for video lectures. Indeed, CTML serves as the theoretical foundation for numerous empirical studies of the effects of video lectures on student outcomes (for example, Wang and Antonenko (2017); Kizilcec, Bailenson and Gomez (2015); Chen and Wu (2015); Hughes, Costley and Lange (2019), among others). Over the last three decades, CTML scholars have iterated between theory and evidence to develop basic and advanced principles of multimedia learning (e.g., Mayer (2009); Mayer and Moreno (2003; 1998); Mayer (2008); Mayer and Anderson (1992)). Although advanced principles can also be incorporated into video lectures, we applied the following seven basic principles during the video lecture redesign event that is at the center of this study: Coherence, Modality, Redundancy, Signaling, Segmenting, Split-Attention, and Personalization. A description of each principle and its underlying logic is presented in Table 1.

Table 1: Multimedia learning principles implemented in video lecture redesign and rerecording

\begin{tabular}{|l|l|}
\hline Coherence Principle: & $\begin{array}{l}\text { People learn better when extraneous narration, sounds, printed text, and visual content are } \\
\text { excluded rather than included. Removing unneeded elements reduces extraneous load } \\
\text { (Mayer, et al., 1996; Harp and Mayer, 1997, 1998). }\end{array}$ \\
\hline Modality Principle: & $\begin{array}{l}\text { People learn better from a combination of pictures and narration than from a combination } \\
\text { of pictures and printed text because processing pictures and narration utilizes dual channels } \\
\text { whereas processing pictures and printed text can overload the visual channel (Mayer and } \\
\text { Moreno, 1998; Moreno and Mayer, 1999; Mousavi, Low and Sweller, 1995). }\end{array}$ \\
\hline Redundancy Principle: & $\begin{array}{l}\text { People learn better when the same information is presented with pictures and narration } \\
\text { rather than with pictures, narration, as well as printed text (Mousavi, Low and Sweller, } \\
\text { 1995) because the printed text is redundant and adds to extraneous load. }\end{array}$ \\
\hline Signaling Principle: & $\begin{array}{l}\text { People learn better when cues are added to direct attention toward essential material } \\
\text { because cues limit extraneous load (Jeung, Chandler and Sweller, 1997; Harp and Mayer, } \\
\text { 1998). }\end{array}$ \\
\hline Segmenting Principle: & $\begin{array}{l}\text { People learn better when multimedia instruction is presented or broken into learner-paced } \\
\text { segments rather than when it is presented as a single, continuous unit (Mayer and } \\
\text { Chandler, 2001). }\end{array}$ \\
\hline Split-Attention Principle: & $\begin{array}{l}\text { People learn better when corresponding visual content and verbal content is presented in } \\
\text { physical and/or temporal proximity. When multimedia is designed such that corresponding } \\
\text { text or narration and visual content are not nearby, the cognitive processing demand } \\
\text { created by searching and integrating separate pieces of information creates extraneous } \\
\text { load for the learner (Mayer and Anderson, 1992; Mayer and Anderson, 1991; Moreno and } \\
\text { Mayer, 1999; Tarmizi and Sweller, 1988). }\end{array}$ \\
\hline $\begin{array}{l}\text { People learn better from multimedia instruction when the instructor's tone and style are } \\
\text { conversational rather than formal because the conversational style is more engaging and } \\
\text { promotes germane load (Moreno and Mayer, 2000; Mayer, et al., 2004). }\end{array}$ \\
\hline Principle:
\end{tabular}

Using the logic of CTML, it stands to reason that designing and producing video lectures in line with the principles of multimedia learning will positively affect students' perceptions of learning and satisfaction. For instance, video lectures designed to not overload the auditory or visual channel and to take advantage of learners' dual channel processing (in line with the Modality Principle) will ease extraneous load and allow the learner to process information more easily. Similarly, video lectures designed in accordance with the Coherence, Redundancy, and Signaling Principles will lighten extraneous load by focusing learners' attention on essential material and by eliminating distracting or redundant elements. In line with the Segmentation Principle, partitioning material into multiple, shorter video lectures will promote cognitive processing by decreasing the material's intrinsic load. Video lectures where related visual and verbal content is presented in proximity (in line with the Split-Attention Principle) will reduce extraneous load by curtailing learners' need to search for and integrate separate pieces of information. In line with the Personalization Principle, video lectures where the instructor's body language and vocal color remain conversational and open bolster germane load and learners' ability to integrate knowledge into long-term memory. In sum, video lecture design and production decisions that limit extraneous and intrinsic load and promote germane load can be expected to reduce cognitive load and free up capacity for knowledge integration. This, in turn, will increase students' perceived learning and feelings of satisfaction. Therefore, we hypothesize: 
Hypothesis 1: Perceived learning will be higher among students exposed to video lectures that are designed and produced in adherence with basic principles of multimedia learning.

Hypothesis 2: Satisfaction will be higher among students exposed to video lectures that are designed and produced in adherence with basic principles of multimedia learning.

\section{Research Context}

\subsection{The Course}

The research context of our study is an online Professional MBA course in Strategic Management at a large, public research university. Nine sections of the course were offered by the program in the years 2016-2019, and all were taught by the same instructor over seven semesters. In 2017, a program-wide decision required that all online MBA courses be designed and developed in collaboration between instructors and instructional designers in accordance with best practices in online instruction. Importantly, the requirement applied not only to new courses yet to be developed, but also to existing online courses previously developed by instructors.

During the initial meeting between the instructor and the instructional designers in 2018, it was agreed that all components of the Strategic Management course could and would remain the same except for the video lectures, which would be redesigned to adhere with best practices and rerecorded in studio by digital media professionals. The video lectures were redesigned and rerecorded during the summer and fall of 2018 with the first students experiencing the redesigned lectures in the Spring semester of 2019. The following course components remained unchanged pre- and post-redesign: assigned readings and cases, discussion boards, quizzes, individual written assignments, group oral presentations, and exams. All course sections also included mandatory, weekly 90-minute synchronous sessions that were oriented toward case discussion and debriefs and were conducted using Zoom (Zoom Video Communications Inc., n.d.). The only difference between the pre- and post-redesign version of the course was therefore the design and production of the video lectures.

\subsection{The Video Lectures}

Unlike existing laboratory experiments which manipulate one or perhaps two multimedia characteristics and measure their effect on learner outcomes, our field study assesses the causal effect of a more comprehensive application of multimedia learning principles in the context of a full-semester course. Given that instructional designers and instructors would also implement all relevant principles of multimedia learning (and not just one) to multimedia content, our findings are realistic and relevant for institutions as they consider adopting video lecture development standards. But, in order to reasonably interpret our findings, it is important to provide context and transparency about the state of the video lectures pre- and post-redesign, and to describe the steps that were taken to improve quality in line with principles of multimedia learning. Below, we outline the implemented changes and specify how each principle was implemented either through redesign or production.

To illustrate how the seven principles described in the Theory and Hypotheses section manifested in the redesigned and rerecorded video lectures, we offer three illustrative examples: presentation of Topic A (in Figures $1 a$ and $1 b$ ), Topic B (in Figures $2 a$ and $2 b$ ), and Topic C (in Figures $3 a$ and $3 b$ ). The same information is being presented for each topic pre- and post-redesign and rerecording - but the difference is in how the information is presented.

For instance, the Modality Principle, which says that people learn better from a combination of pictures and narration than from a combination of pictures and printed text, was implemented during the design process by thoughtfully evaluating what should be presented as printed text what should instead be presented using graphics and narration. For example, the printed text that appears in Figure 1a (but does not appear in Figure 1b) was verbalized by the instructor in the post-redesign version. The printed text that appears in Figure 2a (but does not appear in Figure 2 b) was presented as a graphic post-redesign. 
- The Befter-Off Test

- do the business units create and capture more value if they are related than they could as separate, single-business entities without formal ties?

- factors that matter:

- lower costs: shared activities, shared resources, economies of scale or scope - increased willingness-to-pay!

- The Ownership Test

- do the business units create more value under common ownership than they would through if they were related in other ways?

- are any alternative relationships superior to common ownership?

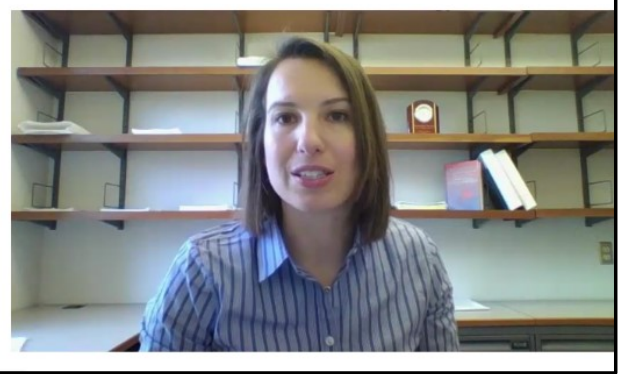

Figure 1a: Screenshot of pre-redesign video lecture on Topic A

\section{Two, Independent Decisions}

\section{\#1: BETTER-OFF TEST}

- Is more value created when business units are:

- Related?

- Separate? (without formal ties)

\section{\#2: OWNERSHIP TEST}

- Is more value created under:

- Common ownership?

- Alternative relationships?

Figure 1b: Screenshot of post-redesign video lecture on Topic A

In line with the Coherence Principle (i.e., people learn better when extraneous narration, sounds, printed text, and visual content are excluded rather than included), extraneous words were removed from the slide title and the bullet points during the redesign (see Figure 1b, compared to Figure 1a). Another example of the Coherence Principle is evident when juxtaposing Figures $2 \mathrm{a}$ and $2 \mathrm{~b}$. Written text and equations that were included in the pre-redesign version (Figure $2 \mathrm{a}$ ) were removed and replaced in the post-redesign version with a simple graphic illustrating the same concept (Figure 2b). Overall, during the redesign, the instructor and the instructional designer emphasized clarity, conservative use of bullet points, impactful graphics, and informative narration in the video lectures. 


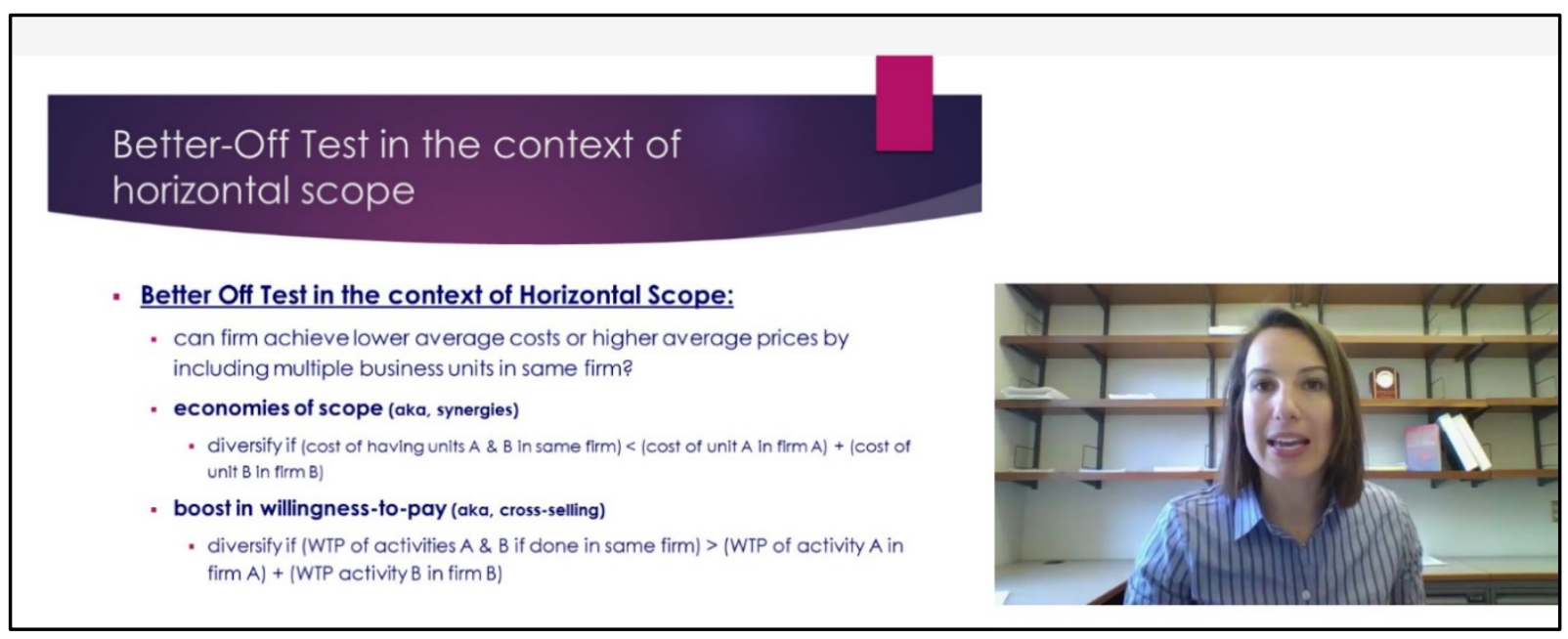

Figure 2a: Screenshot of pre-redesign video lecture on Topic B

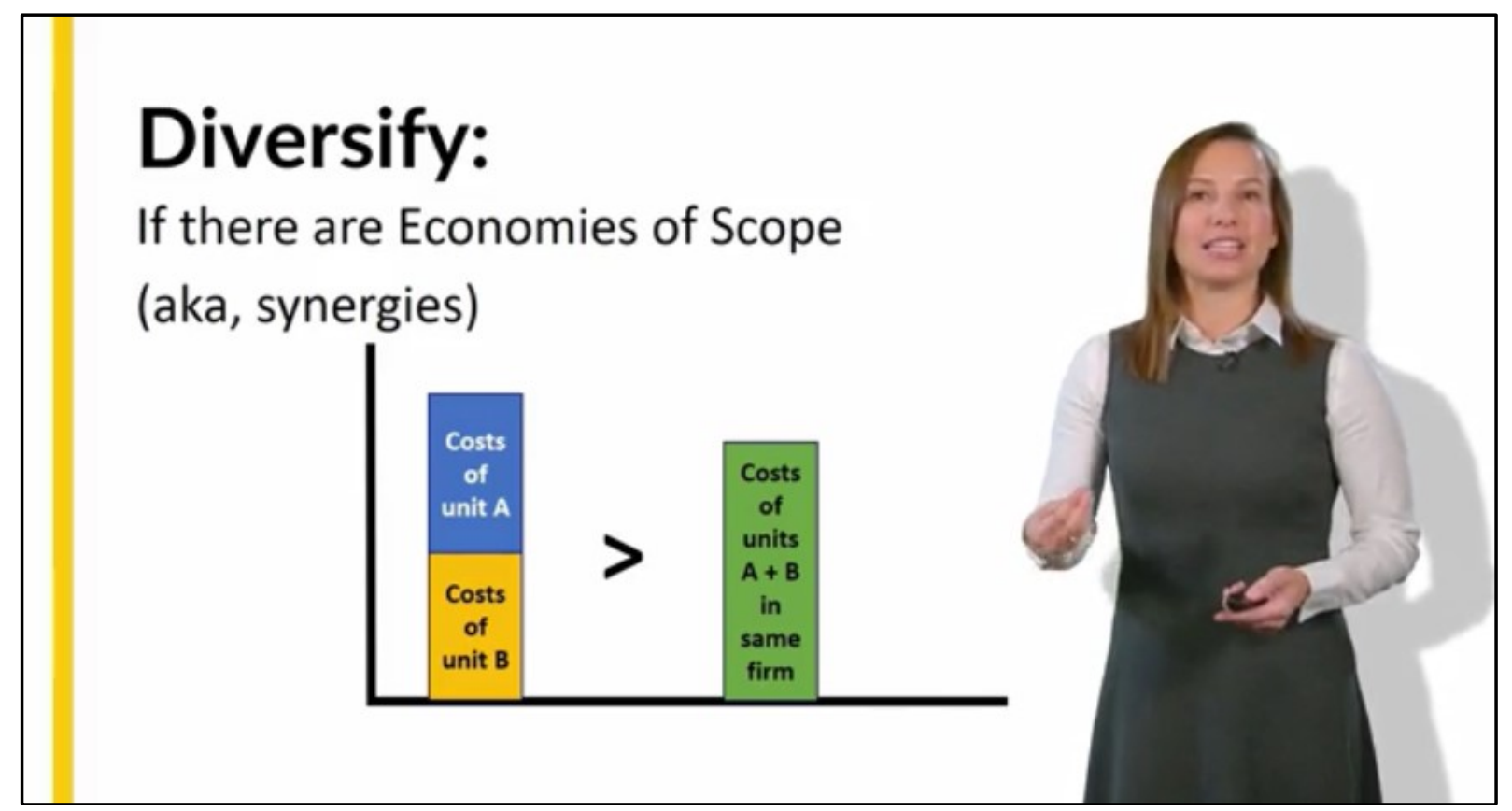

Figure $\mathbf{2 b}$ : Screenshot of post-redesign video lecture on Topic B

A comparison of Figures $3 \mathrm{a}$ and $3 \mathrm{~b}$ illustrates how we implemented the Redundancy Principle (i.e., people learn better when the same information is presented with pictures and narration rather than with pictures, narration, as well as printed text). For example, pre-redesign, the video lecture on Topic $C$ included a graphic, narration describing the graphic, and redundant printed text describing the graphic (Figure 3a). The post-redesign version eases extraneous load by removing the redundant printed text but retaining the graphic and the accompanying narration (Figure $3 b$ ). 


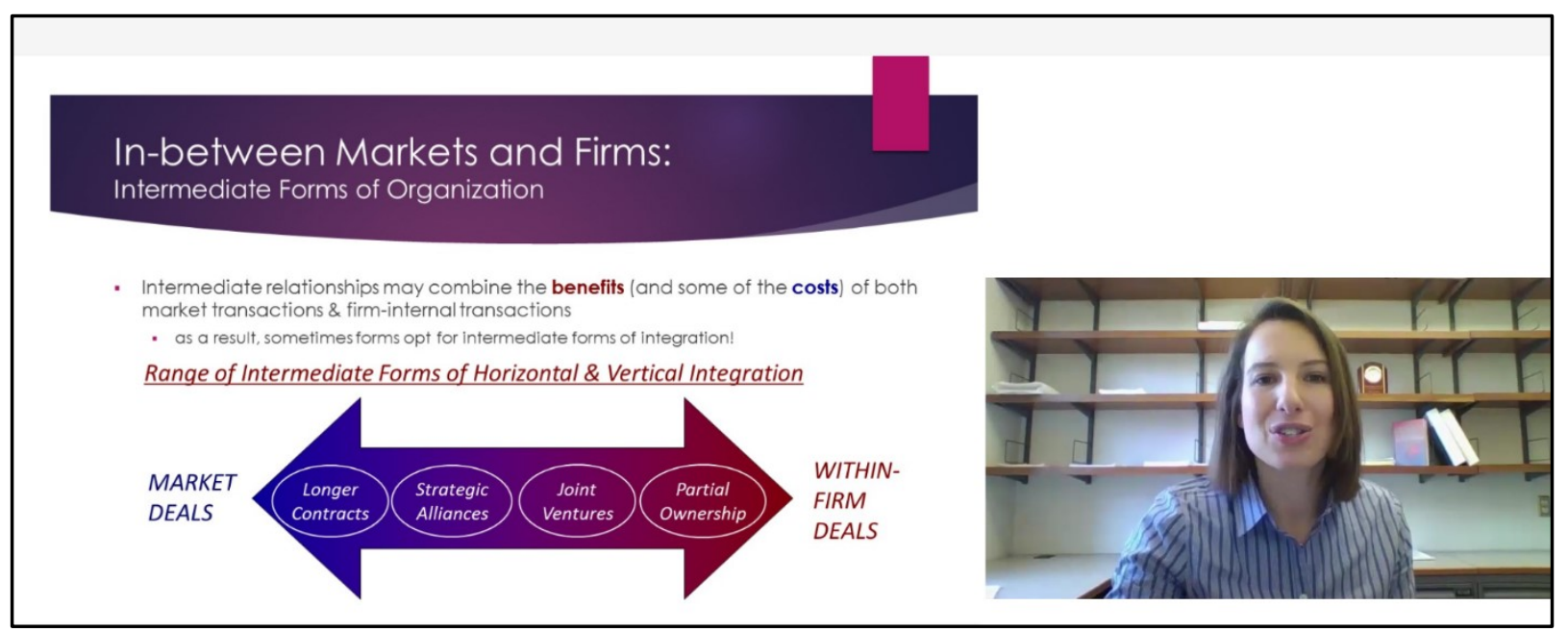

Figure 3a: Screenshot of pre-redesign video lecture on Topic C

\section{In Between Markets and Firms}

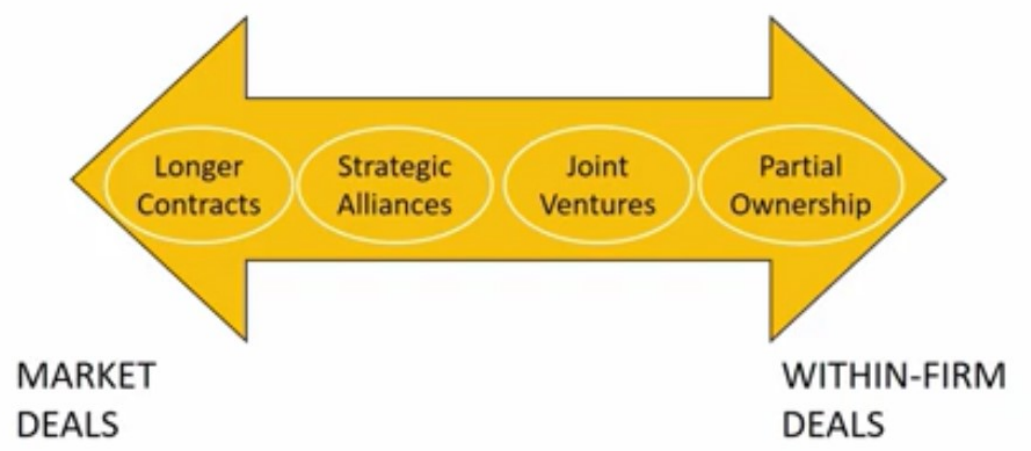

Figure 3b: Screenshot of post-redesign video lecture on Topic C

Pre-redesign, the video lectures showed the instructor's image throughout (as seen in Figures 1a, 2a, and 3a). Post-redesign, the video lectures used instructor presence to signal that students ought to focus their attention on the narration and used the instructor's absence to signal that students needed to tune into the graphics and to the text on slide (as can be seen in Figure 3b, for example). In an application of the Signaling Principle, which says that people learn better when cues are added to direct attention to essential material, the instructor would step off camera when the complexity of the instructional matter was high and would return to the shot when complexity declined.

Another difference pre- and post-redesign relates to the segmentation of the video lectures. Pre-redesign, video lecture length depended on the topic - with the shortest lectures being 21 minutes long and the longest extending to 60 minutes. Yet, the Segmentation Principle indicates that people learn better when multimedia instruction is presented or broken into learner-paced segments rather than being presented as a single, continuous unit. Therefore, during the redesign process, video lectures were broken up and restructured to be no longer than 10 minutes each. Of course, not all topics can be effectively covered in 10 minutes and therefore some topics were covered in two or even three 10-minute lectures. Overall, the total video lecture time was 
shorter post-redesign than pre-redesign (222 minutes and 266 minutes, respectively), but remained comparable. The segmentation of the lectures, however, differed considerably.

The other principles were implemented through production. Comparing Figure 1a with Figure $1 \mathrm{~b}$ (and Figure 2a with Figure 2b) illustrates how we applied the Split-Attention Principle (i.e., people learn better when corresponding visual and verbal content is physically proximate). The pre-version presents the instructor in a separate window while the post-version superimposes the instructor's presence over the slides. The production change doesn't eliminate gaze switching between the instructor and the content, but the instructor is physically closer and seamlessly integrated with the content post-redesign, reducing students' extraneous load when processing the multimedia. Finally, the Personalization Principle (which says that people learn better from multimedia instruction when the instructor's tone and style are conversational rather than formal) is embodied in the instructor's position. While the production style of the pre-version shows the instructor behind the office desk, there is no barrier between the student and the instructor in post-version and the instructor's body language is open, which is thought to increase germane load.

\section{Method}

\subsection{Sample and Data Collection}

405 students enrolled in and completed the online Strategic Management course. Each course section was capped at 45 students and was always fully subscribed, resulting in equal class sizes. Upon the culmination of the course, students were asked to evaluate course quality using standardized questions administered via an online evaluation system. Of the 405 enrolled students, 300 students completed the non-mandatory course evaluation survey at the end of the semester (corresponding to a 74 percent response rate). These students represent the study sample.

Of the 300 students in the sample, 194 students took the course in the years 2016-2018 and were exposed to video lectures developed and produced by the instructor. These students comprise the control group. The remaining 106 responses are from students who took the course in 2019 and were exposed to video lectures that were designed and developed in collaboration between the instructor and instructional designers and recorded in studio. These represent the treatment group.

This study was conducted in accordance with ethical principles for behavioral research. The Institutional Review Board (IRB) approved this study (IRB ID\# 201905845) and waived informed consent by the study's student research subjects.

\subsection{Measures}

\subsubsection{Dependent Variables}

Perceived learning and student satisfaction are commonly used dependent variables in studies of online courses (Arbaugh, 2005b; Marks, Sibley and Arbaugh, 2005; Alavi, Marakas and Yoo, 2002) and video lectures (Wang and Antonenko, 2017; Kizilcec, Bailenson and Gomez, 2015; Costley and Lange, 2017). A major challenge facing online education is the comparatively high voluntary attrition rate among students (Bawa, 2016). Perceived learning and student satisfaction predict retention (Hone and El Said, 2016) and students' intentions to complete a degree online (Lorenzo, 2012; Yukselturk and Yildirim, 2008), making these constructs critical for both theory and practice (Alavi, Marakas and Yoo, 2002; Marks, Sibley and Arbaugh, 2005). Of course, comprehension and learning retention are the primary goals of education. However, online education is also a product where earned revenues through tuition depend on students' perceptions of quality. For these reasons, we examined perceived learning and student satisfaction as the outcomes of interest.

The dependent variables were derived from student responses to the course evaluation survey. The course evaluation survey consists of 11 items that address multiple instructional dimensions, each utilizing a 6-point response scale ranging from $1=$ 'strongly disagree' to $6=$ 'strongly agree.' To proxy for Perceived learning, we used students' responses to the survey item: "Concepts are presented in a manner that helps me learn." To proxy for Student satisfaction, we used students' responses to the survey item: "I would recommend a course taught by this instructor to other students." Because video lectures were the only feature of the course to change pre- and post-redesign and were the core of the presented material, these items capture the change in students' perceived learning and satisfaction. 


\subsubsection{Independent Variable}

Video lecture quality is a binary variable set equal to 1 if the student was exposed to video lectures that were designed and produced in collaboration between the instructor and the instructional designer in line with multimedia learning principles. The variable was set equal to 0 if the student was exposed to video lectures that were designed and produced by the instructor.

\subsubsection{Control Variables}

We also controlled for variance in contextual factors that prior research indicates could affect perceived learning and student satisfaction. Between 2016-2019, the course was offered in three formats: a 12-week session, 11week session, and 6-week session. Studies show that condensed courses can affect student course evaluations and therefore the regression analyses controlled for Course length, measured in weeks. Class time has also been found to be correlated with student course evaluations (Husbands and Fosh, 1993) and we controlled for the start time of the weekly, synchronous Zoom sessions. Course time is a binary variable set equal to 1 if the synchronous Zoom session started at $8 \mathrm{PM}$ and set equal to 0 if it began at 6 PM. Finally, research indicates that a student's expected grade in the course also influences the course evaluation (Braskamp and Ory, 1994; Marsh, 1987). We controlled for student performance in the course by including the Course grade. Students' responses to the course evaluation survey are de-identified, so we couldn't match individuals' evaluations to their grade in the course. We instead used the section average grade (in grade point average format).

Additional class-related and instructor-related characteristics, such as class size (Arbaugh and Duray, 2002), subject matter (Arbaugh, 2005a), and instructor attributes (Arbaugh and Duray, 2002) are also known to be correlated with students' perceptions of online courses, but these remained constant in this research study.

\section{Results}

Table 2 presents descriptive statistics for the independent and control variables for the full sample and for the two sub-samples. Table 3 presents Pearson correlation coefficients between study variables.

Table 2: Descriptive statistics of independent and control variables

\begin{tabular}{|c|c|c|c|}
\hline & All observations & Pre-redesign & Post-redesign \\
\hline & & \multicolumn{2}{|c|}{ Mean (Standard deviation) } \\
\hline $\begin{array}{l}\text { Perceived learning } \\
\text { (scale 1-6) }\end{array}$ & $5.38(0.87)$ & $5.25(0.92)$ & $5.61(0.70)$ \\
\hline $\begin{array}{l}\text { Student satisfaction } \\
\text { (scale 1-6) }\end{array}$ & $5.58(0.82)$ & $5.49(0.93)$ & $5.75(0.51)$ \\
\hline $\begin{array}{l}\text { Course length } \\
\text { (in weeks) }\end{array}$ & $10.21(2.41)$ & $9.77(2.91)$ & $11(0.00)$ \\
\hline $\begin{array}{l}\text { Course time } \\
(6 \mathrm{PM}=0,8 \mathrm{PM}=1)\end{array}$ & $0.32(0.47)$ & $0.14(0.35)$ & $0.65(0.48)$ \\
\hline \multirow[t]{2}{*}{$\begin{array}{l}\text { Course grade } \\
\text { (class section grade } \\
\text { average in G.P.A. format) }\end{array}$} & $3.64(0.09)$ & $3.65(0.11)$ & $3.62(0.06)$ \\
\hline & $\mathrm{n}=300$ & $n=194$ & $\mathrm{n}=106$ \\
\hline
\end{tabular}

Table 3: Pearson correlation coefficients

\begin{tabular}{|r|l|l|l|l|l|l|l|}
\hline & & 1 & 2 & 3 & 4 & 5 & 6 \\
\hline 1 & Video lecture quality & 1.00 & & & & & \\
\hline 2 & Perceived learning & $0.20^{* * *}$ & 1.00 & & & & \\
\hline 3 & Student satisfaction & $0.16^{* *}$ & $0.70^{* * *}$ & 1.00 & & & \\
\hline 4 & Course length & $0.24^{* * *}$ & $0.16^{* *}$ & $0.19^{* * *}$ & 1.00 & & \\
\hline 5 & Course time & $0.52^{* * *}$ & $0.16^{* *}$ & $0.14^{*}$ & $0.31^{* * *}$ & 1.00 & \\
\hline 6 & Course grade average & -0.11 & $0.12^{*}$ & 0.02 & $-0.34^{* * *}$ & $0.21^{* * *}$ & 1.00 \\
\hline
\end{tabular}

Table 4 reports differences in means in the dependent variables for the control and treatment group and gives us our first insights into the research questions. The $t$-tests show that there is a statistically significant difference 
and increase in both Perceived learning $(p<0.001)$ and Student satisfaction $(p<0.01)$ following the video lecture redesign and rerecording. To interpret the effect size, we calculated Cohen's $d$ (Cohen, 1988), which quantifies the difference in magnitude between two intervention groups in units of standard deviation. Using this approach, the video lecture redesign had a small to medium effect on both Perceived learning $(d=0.41)$ and Student satisfaction $(d=0.33)$, providing initial support for both hypotheses.

Table 4: Differences in dependent variable means pre- and post-redesign of video lectures

\begin{tabular}{|l|c|c|c|}
\hline & Perceived learning & Student satisfaction & $\mathrm{N}$ \\
\hline Pre-redesign & $5.25(0.92)$ & $5.49(0.93)$ & 194 \\
\hline Post-redesign & $5.61(0.70)$ & $5.75(0.51)$ & 106 \\
\hline Student t-statistic & 3.45 & 2.72 & \\
\hline$p$ & $<0.001$ & $<0.01$ & \\
\hline Effect size (Cohen's d) & $0.41[0.18,0.66]$ & $0.33[0.09,0.57]$ & \\
\hline
\end{tabular}

\subsection{Regression Discontinuity Results}

We used a regression discontinuity design (Lee and Lemiux, 2010) to make a causal inference about the effect of video lecture design and production on student outcomes. To test our hypotheses, we performed ordinaryleast squares (OLS) regressions of the control and independent variables on Perceived learning and Student satisfaction. We clustered the standard errors by course section.

Table 5 reports the results of the effect of Video lecture quality on Perceived learning and shows that, controlling for covariates, Video lecture quality is a positive and statistically significant predictor $(\beta=0.36, p=0.02)$ of Perceived learning. The results provide strong support for Hypothesis 1. Table 6 shows the results of the effect of Video lecture quality on Student satisfaction. Increasing Video lecture quality has a positive but weakly significant effect on Student satisfaction $(6=0.20, p=0.08)$, providing weak support for Hypothesis 2 .

Table 5: Ordinary least-squares regression analyses of perceived learning

\begin{tabular}{|l|c|c|}
\hline \multicolumn{3}{|l|}{ Dependent variable: Perceived learning } \\
\hline & Model 1 & Model 2 \\
\hline Video lecture quality & & $0.36^{*}$ \\
\hline & & {$[0.02]$} \\
\hline Course length & 0.07 & $0.07^{*}$ \\
\hline & {$[0.08]$} & {$[0.03]$} \\
\hline Course time & 0.12 & -0.09 \\
\hline \multicolumn{2}{|l|}{$[0.41]$} & {$[0.50]$} \\
\hline Course grade & $1.57^{*}$ & $2.00^{* *}$ \\
\hline \multicolumn{2}{|l|}{$[0.01]$} & {$[0.00]$} \\
\hline Constant & -1.09 & -2.75 \\
\hline \multicolumn{2}{|l|}{} & {$[0.16]$} \\
\hline Observations & {$[0.57]$} & 300 \\
\hline R-squared & 300 & 0.09 \\
\hline$P$ values are shown in brackets. & 0.06 \\
\hline$* * * p<0.001, * * p<0.01, * p<0.05$ & \\
\hline
\end{tabular}


Table 6: Ordinary least-squares regression analyses of student satisfaction

\begin{tabular}{|l|c|c|}
\hline \multicolumn{3}{|l|}{ Dependent variable: Student satisfaction } \\
\hline & Model 3 & Model 4 \\
\hline Video lecture quality & & 0.20 \\
\hline & & {$[0.08]$} \\
\hline Course length & 0.07 & 0.07 \\
\hline & {$[0.20]$} & {$[0.17]$} \\
\hline Course time & 0.12 & 0.00 \\
\hline & {$[0.33]$} & {$[0.98]$} \\
\hline Course grade & 0.62 & 0.87 \\
\hline \multicolumn{2}{|l|}{} & {$[0.19]$} \\
\hline Constant & {$[0.29]$} & 1.65 \\
\hline \multicolumn{2}{|l|}{} & {$[0.51]$} \\
\hline Observations & 2.59 & 300 \\
\hline R-squared & {$[0.27]$} & 0.06 \\
\hline$P$ values are shown in brackets. \\
\hline$* * * p<0.001, * * p<0.01, * p<0.05$ \\
\hline
\end{tabular}

Since both Perceived learning and Student satisfaction are measured using an ordinal scale from 1-6, we performed ordered logistic regressions for both dependent variables with the same specifications as above (not shown) as robustness checks. The results are in line with those of the reported OLS regressions.

\section{Discussion}

\subsection{Noteworthy Findings and Implications for Theory}

Our results show that designing and producing video lectures in accordance with principles of multimedia learning has a meaningful causal effect on students' perceived learning. After implementing multimedia learning principles into video lectures (and holding all else equal), instructors can expect a 0.41 standard deviation increase in perceived learning. Instructors may also experience an increase in student satisfaction; however, our analyses only uncovered a weakly significant effect of video lecture quality on student satisfaction. Previously, our knowledge of these relationships rested on small-sample laboratory studies and field studies in contexts that are dissimilar to graduate-level online programs in the U.S. (such as undergraduate courses, courses at institutions outside the U.S., MOOCs, and Amazon Mechanical Turk participants). Our study therefore contributes an important result to video lecture research and to the growing literature on online graduate education.

Our study of video lecture design and production also contributes to evidence-based research on CTML. After simultaneously implementing seven multimedia learning principles in our video lectures, it is noteworthy that our effect sizes are on the lower end of the range reported by experimental studies that examined the effect of individual multimedia principles on student outcomes: Coherence Principle (median $d=0.86 ; 23$ experiments) (Mayer and Fiorella, 2014); Modality Principle (median $d=0.76,61$ experiments) (Mayer and Pilegard, 2014); Signaling Principle (median $d=0.41,28$ experiments) (Mayer and Fiorella, 2014); Redundancy Principle (median $d=0.86,16$ experiments) (Mayer and Fiorella, 2014); Segmenting Principle (median $d=0.79,10$ experiments) (Mayer and Pilegard, 2014); and Personalization Principle (median $d=0.79,17$ experiments) (Mayer, 2014c). One possible reason is that laboratory environments differ substantially from full-semester online graduate courses. In contrast to value-added laboratory studies, where participants are presented with multimedia and the studies test the effect of a singular change on learner outcomes, the success of full-semester courses depends on a multitude of factors. It depends not only on lecture quality, but also on the quality of assignments, exams, student-to-student interaction, student-to-instructor interaction, perceived fairness in grading, etc. In our case, the other course components did not change pre- and post-redesign and rerecording, but they nonetheless represented a nontrivial part of the students' overall experience. These other course components were also already satisfactory from the students' perspective (as evidenced by the relatively high student evaluations from before the video lecture redesign) and therefore our findings are likely constrained by a ceiling effect (Bakker, et al., 2019). The magnitudes of the observed effects therefore need to be interpreted within the context of an otherwise effective, full-semester online graduate course (Bakker, et al., 2019). 
We also note a bigger effect of the video lecture redesign on perceived learning than on satisfaction. On the one hand, Student satisfaction was already quite high pre-redesign (5.49 out of 6) and Perceived learning was comparatively lower pre-redesign (5.26 out of 6). But the bigger increase in Perceived learning after the redesign and rerecording also indicates that students in this study responded not only to the higher production quality of the in-studio recording (which would be expected to increase satisfaction but not necessarily learning), but to the efforts made to increase germane load and decrease extraneous and intrinsic load through application of multimedia learning principles.

\subsection{Implications for Practice}

As online graduate programs consider how to best allocate limited resources, our findings offer useful empirical evidence on whether to invest into instructional designers and professional production when creating video lectures. As mentioned in the introduction, the cost of designing and developing online learning content in line with best practices is substantial. Are increases of 0.41 standard deviations in perceived learning and 0.33 standard deviations in student satisfaction worth the financial cost of implementation (not to mention the energy and opportunity cost of faculty members' time)?

From a pedagogical perspective the answer is clearly yes because student outcomes improved. From a financial perspective, however, the conclusion may depend on the nature of the video lecture content, what purpose the video lectures serve in the course, and how often the video lectures need to be changed. If video lectures are the primary means of disseminating content in the course and the lecture can be reused over multiple academic years, then investment is more likely to be worthwhile. However, if students' perceived learning and satisfaction are already high or the video lectures need to be re-developed often (to remain current given advances in the field, for instance), then the rise in students' perceptions may not be worth the added cost of professional design and production.

Finally, the disruption caused by the pandemic has made efficient online instruction a top priority for administrators and faculty members alike. It has also highlighted that educational theory for online learning matters. Our study contributes to this conversation by not only describing how online instruction can be improved through video lecture design and production, but also by quantifying the effect of applying principles of multimedia learning to video lectures on student outcomes.

\subsection{Limitations and Directions for Future Research}

There are certainly several limitations to this study that need to be considered when interpreting the findings. Although this is a multi-semester study with hundreds of participants, the data derive from a Strategic Management course taught by one instructor. From previous research, we know that disciplinary (Arbaugh, 2005a; Arbaugh and Rau, 2007) and instructor-specific effects induce variance in students' perceptions of online courses. Therefore, the effect of video lectures on student outcomes also needs to be studied across disciplines and instructors (Arbaugh, et al., 2009). Since dispositional, behavioral, and demographic characteristics may influence students' perceptions of video lectures, instructor-centered research would be valuable and would enhance our understanding of what works, what doesn't, and under what conditions.

Also, we examined the effect of our intervention on perceived learning. The long-term goal of instruction is, of course, comprehension and retention of the material. Therefore, it is important that future studies examine whether adoption of best practices in video lectures facilitates not only the perception of learning but also comprehension and retention.

\section{Conclusion}

We began this study with an interest in whether implementation of multimedia learning principles in video lectures matters for student outcomes. We pursued this analysis after finding misalignment between educational theory and practice in online learning. While research shows that implementing best practices in online course design increases learning and satisfaction, institutions are not investing sufficiently in training and support which would empower faculty to implement advances in online learning research into practice (Garrett, Legon and Fredericksen, 2019). Many faculty members also remain skeptical of online learning pedagogy and are reticent about giving up their autonomy while working with instructional designers (Garrett, Legon and Fredericksen, 2019). We used the context of video lecture design and production to measure how much adherence to best practices matters for perceived learning and student satisfaction. We exploited an exogenous 
change in online course development standards in an MBA program at a large, research university, providing much needed empirical evidence for online graduate education.

Based the results of this study, the following conclusions can be made. Designing and producing video lectures in accordance with multimedia learning principles has a positive causal effect on perceived learning of 0.41 standard deviations and a weakly positive causal effect on student satisfaction of 0.33 standard deviations.

\section{References}

Alavi, M., Marakas, G. M. and Yoo, Y., 2002. A comparative study of distributed learning environments on learning outcomes. Information Systems Research, 13(4), pp.404-415.

Arbaugh, J. B., 2005a. How much does "subject matter" matter? A study of disciplinary effects in on-line MBA courses. Academy of Management Learning \& Education, 4(1), pp.57-73.

Arbaugh, J. B., 2005b. Is there an optimal design for on-line MBA courses? Academy of Management Learning \& Education, 4(2), pp.135-149.

Arbaugh, J. B. and Duray, R., 2002. Technological and structural characteristics, student learning and satisfaction with webbased courses: an exploratory study of two MBA programs. Management Learning, 33(3), pp.331-347.

Arbaugh, J. B., Godfrey, M. R., Johnson, M., Leisen Pollack, B., Niendorf, B. and Wresch, W., 2009. Research in online and blended learning in the business disciplines: key findings and possible future directions. Internet and Higher Education, 12(2), pp.71-87.

Arbaugh, J. B. and Rau, B. L., 2007. A study of disciplinary, structural, and behavioral effects on course outcomes in online MBA courses. Decision Sciences Journal of Innovative Education, 5(1), pp.65-95.

Baddeley, A., 1986. Working memory. New York: Oxford University Press.

Baddeley, A., 1992. Working memory. Science, 255(5044), pp.556-559.

Bakker, A., Cai, J., English, L., Kaiser, G., Mesa, V. and Van Dooren, W., 2019. Beyond small, medium, or large: points of consideration when interpreting effect sizes. Educational Studies in Mathematics, 102(1), pp.1-8.

Bawa, P., 2016. Retention in online courses: exploring issues and solutions - a literature review. SAGE Open, JanuaryMarch(January-March), pp.1-11.

Bhat, S., Chinprutthiwong, P. and Perry, M. 2015. Seeing the instructor in two video styles: preferences and patterns. 8th International Conference on Educational Data Mining. Madrid, Spain: International Educational Data Mining Society.

Braskamp, L. and Ory, J., 1994. Assessing faculty work: enhancing individual and institutional performance. San Fransisco: Jossey-Bass.

Chandler, P. and Sweller, J., 1991. Cognitive load theory and the format of instruction. Cognition and Instruction, 8(4), pp.293-332.

Chen, C.-M. and Wu, C.-H., 2015. Effects of different video lecture types on sustained attention, emotion, cognitive load, and learning performance. Computers \& Education, 80(January), pp.108-121.

Clark, R. C. and Mayer, R. E., 2011. E-learning and the science of instruction: proven guidelines for consumers and designers of multimedia learning. San Francisco, CA: Pfeiffer.

Cohen, J., 1988. Statistical power analysis for the behavioral sciences. Mahwah, NJ: Lawrence Erlbaum Associates.

Costley, J. and Lange, C. H., 2017. Video lectures in e-learning: effects of viewership and media diversity on learning, satisfaction, engagement, interest, and future behavioral intention. Interactive Technology and Smart Education, 14(1), pp.14-30.

Crook, C. and Shofield, L., 2017. The video lecture. The Internet and Higher Education, 34(July), pp.56-64.

De Koning, B. B., Hoogerheide, V. and Boucheix, J.-M., 2018. Development and trends in learning with instructional video. Computers in Human Behavior, 89(1), pp.395-398.

Draus, P. J., Curran, M. J. and Trempus, M. S., 2014. The influence of instructor-generated video content on student satisfaction with and engagement in asynchronous online classes. MERLOT Journal of Online Learning and Teaching, 10(2), pp.240-254.

Fiorella, L., Van Gog, T., Hoogerheide, V. and Mayer, R. E., 2017. It's all a matter of perspective: viewing first-person video modeling examples promotes learning of an assembly task. Journal of Educational Psychology, 109(5), pp.653-665.

Garrett, R., Legon, R. and Fredericksen, E. E. 2019. CHLOE 3 Behind the numbers: the changing landscape of online education 2019. Quality Matters.

Garrison, D. R. and Arbaugh, J. B., 2007. Researching the community of inquiry framework: review, Issues, and future directions. The Internet and Higher Education, 10(3), pp.157-172.

Guo, P. J., Kim, J. and Rubin, R., 2014. How video production affects student engagement: an empirical study of MOOC videos. Proceedings of the first ACM Conference on Learning at Scale, 1(1), pp.41-50.

Harp, S. F. and Mayer, R. E., 1997. The role of interest in learning from scientific text and illustrations: on the distinction between emotional interest and cognitive interest. Journal of Educational Psychology, 89(1), pp.92-102.

Harp, S. F. and Mayer, R. E., 1998. How seductive details do their damage: a theory of cognitive interest in science learning. Journal of Educational Psychology, 90(3), pp.414-434.

Hone, K. S. and El Said, G. R., 2016. Exploring the factors affecting MOOC retention: a survey study. Computers \& Education, 98(July), pp.157-168. 
Hong, J., Pi, Z. and Yang, J., 2018. Learning declarative and procedural knowledge via video lectures: cognitive load and learning effectiveness. Innovations in Education and Teaching International, 55(1), pp.74-81.

Hughes, C., Costley, J. and Lange, C. H., 2019. The effects of multimedia video lectures on extraneous load. Distance Education, 40(1), pp.54-75.

Husbands, C. and Fosh, P., 1993. Students' evaluation of teaching in higher education: experiences from four European countries and some implications of the practice. Assessment and Evaluation in Higher Education, 18(2), pp.95-114.

Jaschik, S. and Lederman, D. 2019. The 2019 Inside Higher Ed survey of faculty attitudes on technology. Inside Higher Ed.

Jenlink, P. M. ed., 2019. Multimedia learning theory: preparing for the new generation of students. London, UK: Rowman \& Littlefield.

Jeung, H., Chandler, P. and Sweller, J., 1997. The role of visual indicators in dual sensory mode instruction. Educational Psychology, 17(3), pp.329-345.

Ke, F., 2010. Examining online teaching, cognitive, and social presence for adult learners. Computers \& Education, 55(2), pp.808-820.

Kenny, R. F., Zhang, Z., Schwier, R. A. and Campbell, K., 2005. A review of what instructional designers do: questions answered and questions not asked. Canadian Journal of Learning and Technology, 31(1), pp.9-26.

Kizilcec, R. F., Bailenson, J. N. and Gomez, C. J., 2015. The instructor's face in video instruction: evidence from two largescale field studies. Journal of Educational Psychology, 107(3), pp.724-739.

Lee, D. S. and Lemiux, T., 2010. Regression discontinuity designs in economics. Journal of Economic Literature, 48(2), pp.281-355.

Lorenzo, G., 2012. A research review about online learning: are students satisfied? Who do some succeed and others fail? What contributes to higher retention rates and positive learning outcomes? Internet Learning, 1(1), pp.46-55.

Magda, A. J. and Aslanian, C. B. 2018. Online college students 2018: comprehensive data on demands and preferences. Louisville, KY: The Learning House, Inc.

Marks, R. B., Sibley, S. D. and Arbaugh, J. B., 2005. A structural equation model of predictors for effective online learning. Journal of Management Education, 29(4), pp.531-563.

Marsh, H. W., 1987. Students' evaluations of university teaching: research findings, methodological issues, and directions for future research. International Journal of Educational Research, 11(3), pp.253-388.

Mayer, R. E. ed., 2005. The Cambridge handbook of multimedia learning. New York: Cambridge University Press.

Mayer, R. E., 2008. Applying the science of learning: Evidence-based principles for the design of multimedia instruction. American Psychologist, 63(8), pp.760-769.

Mayer, R. E., 2009. Multimedia learning. New York: Cambridge University Press.

Mayer, R. E. ed., 2014a. The Cambridge handbook of multimedia learning. New York: Cambridge University Press.

Mayer, R. E., 2014b. Cognitive theory of multimedia learning. In: R. E. Mayer, ed. 2014b. The Cambridge handbook of multimedia learning. 2nd ed. New York: Cambridge University Press. pp.43-71.

Mayer, R. E., 2014c. Principles based on social cues in multimedia learning: personalization, voice, image, and embodiment principles. In: R. E. Mayer, ed. 2014c. The Cambridge handbook of multimedia learning. 2nd ed. New York: Cambridge University Press. pp.345-368.

Mayer, R. E. and Anderson, R., 1991. Animations need narrations: an experimental test of dual-coding hypothesis. Journal of Educational Psychology, 83(4), pp.484-490.

Mayer, R. E. and Anderson, R. B., 1992. The instructive animation: helping students build connections between words and pictures in multimedia learning. Journal of Educational Psychology, 84(4), pp.444-452.

Mayer, R. E., Bove, W., Bryman, A., Mars, R. and Tapangco, L., 1996. When less is more: meaningful learning from visual and verbal summaries of science textbook lessons. Journal of Educational Psychology, 88(1), pp.64-73.

Mayer, R. E. and Chandler, P., 2001. When learning is just a click away: does simple user interaction foster deeper understanding of multimedia messages. Journal of Educational Psychology, 93(2), pp.390-397.

Mayer, R. E., Fennell, S., Farmer, L. and Campbell, J., 2004. A personalization effect in multimedia learning: students learn better when words are in conversational style rather than formal style. Journal of Educational Psychology, 96(2), pp.389-395.

Mayer, R. E. and Fiorella, L., 2014. Principles for reducing extraneous processing in multimedia learning: coherence, signaling, redundancy, spatial contiguity, and temporal contiguity principles. In: R. E. Mayer, ed. 2014. The Cambridge handbook of multimedia learning. 2nd ed. New York: Cambridge University Press. pp.279-315.

Mayer, R. E. and Moreno, R., 1998. A split-attention effect in multimedia learning: evidence for dual processing systems in working memory. Journal of Educational Psychology, 90(2), pp.312-320.

Mayer, R. E. and Moreno, R., 2003. Nine ways to reduce cognitive load in multimedia learning. Educational Psychologist, 38(1), pp.43-52.

Mayer, R. E. and Pilegard, C., 2014. Principles for managing essential processing in multimedia learning: segmenting, pretraining, and modality principles. In: R. E. Mayer, ed. 2014. The Cambridge handbook of multimedia learning. 2 nd ed. New York: Cambridge University Press. pp.316-344.

Miller, G. A., 1956. The magical number seven plus or minus two: some limits on our capacity for processing information. Psychological Review, 63(2), pp.81-97.

Moreno, R. and Mayer, R. E., 1999. Cognitive principles of multimedia learning: the role of modality and contiguity. Journal of Educational Psychology, 91(2), pp.358-368. 
Moreno, R. and Mayer, R. E., 2000. Engaging students in active learning: the case for personalized multimedia messages. Journal of Educational Psychology, 92(4), pp.724-733.

Mosley, P. L., 2017. Lecture video: characteristics and utilizations as an online learning resource. In: P. M. Sörensen and D. A. Canelas, ed. 2017. Online Approaches to Chemical Education. Washington, D.C.: American Chemical Society. pp.91100.

Mousavi, S., Low, R. and Sweller, J., 1995. Reducing cognitive load by mixing auditory and visual presentation modes. Journal of Educational Psychology, 87(2), pp.319-334.

Movchan, S., Radchenko, A., Ostler, R. and Koblyakov, P. 2019. How much does it cost to create an online course? Available at: https://raccoongang.com/blog/how-much-does-it-cost-create-online-course/ [Accessed 17 October 2019].

Paas, F. and Sweller, J., 2014. Implications of cognitive load theory for multimedia learning. In: R. E. Mayer, ed. 2014. The Cambridge handbook of multimedia learning. 2nd ed. New York: Cambridge University Press. pp.27-42.

Paivio, A., 1990. Mental representations: a dual coding approach. New York: Oxford University Press.

Penney, C. G., 1989. Modality effects and the structure of short-term verbal memory. Memory and Cognition, 17(4), pp.398-422.

Sweller, J., 1988. Cognitive load during problem solving: effects on learning. Cognitive Science, 12(2), pp.257-285.

Sweller, J., 1994. Cognitive load theory, learning difficulty, and instructional design. Learning and Instruction, 4(4), pp.295312.

Sweller, J., 2005. Implications of cognitive load theory for multimedia learning. In: R. E. Mayer, ed. 2005. The Cambridge handbook of multimedia learning. Cambridge, UK: Cambridge University Press. pp.19-30.

Sweller, J., 2010. Element interactivity and intrinsic, extraneous, and germane cognitive load. Educational Psychology Review, 22(2), pp.123-138.

Tarmizi, R. and Sweller, J., 1988. Guidance during mathematical problem-solving. Journal of Educational Psychology, 80(4), pp.424-436.

Van Wermeskerken, M., Ravensbergen, S. and Van Gog, T., 2018. Effects of instructor presence in video modeling examples on attention and learning. Computers in Human Behavior, 89(December), pp.430-438.

Van Wermeskerken, M. and Van Gog, T., 2017. Seeing the instructor's face and gaze in demonstration video examples affects attention allocation but not learning. Computers \& Education, 113(October), pp.98-107.

Wang, J. and Antonenko, P. D., 2017. Instructor presence in instructional video: effects on visual attention, recall, and perceived learning. Computers in Human Behavior, 71(June), pp.79-89.

Wilson, K. E., Martinez, M., Mills, C., D'mello, S. and Smilek, S., 2018. Instructor presence effect: liking does not always lead to learning. Computers \& Education, 122(July), pp.205-220.

Wittrock, M. C., 1989. Generative processes of comprehension. Educational Psychologist, 24(4), pp.345-376.

Yukselturk, E. and Yildirim, Z., 2008. Investigation of interaction, online support, course structure and flexibility as the contributing factors to students' satisfaction in an online certificate program. Educational Technology \& Society, 11(4), pp.51-65.

Zoom Video Communications Inc., n.d. Zoom Meetings. Available at: https://zoom.us [Accessed 15 April 2020]. 